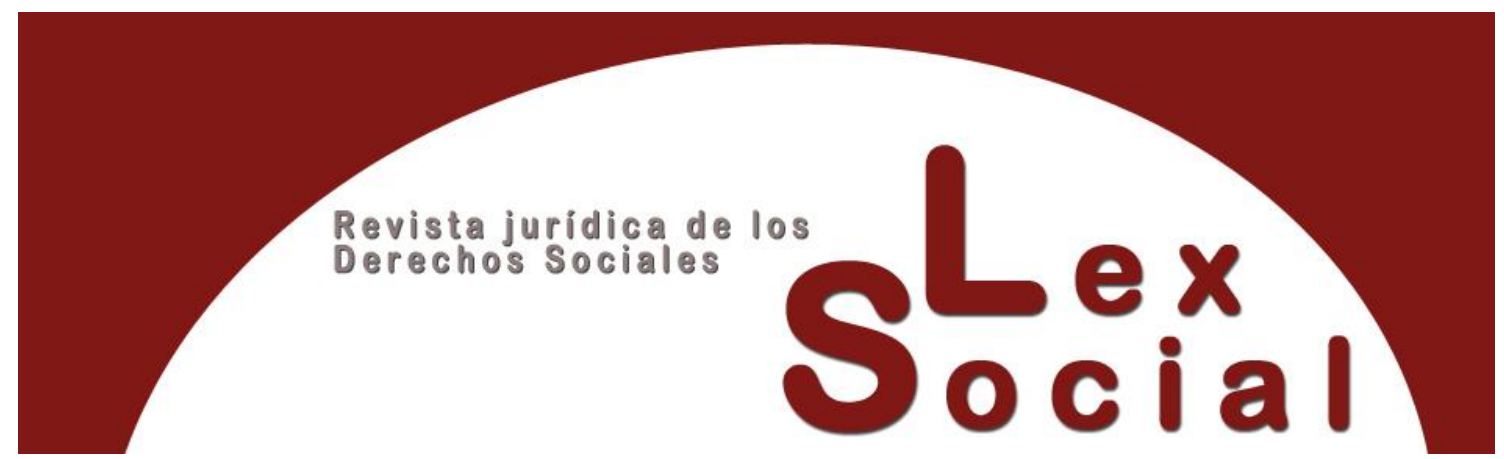

\title{
LA NEGOCIACIÓN COLECTIVA EN LA FUNCIÓN PÚBLICA EN PORTUGAL Y ESPAÑA: UNA APORTACIÓN PARA EL DEBATE
}

THE COLLECTIVE BARGAINING IN THE CIVIL SERVICE IN PORTUGAL AND SPAIN: A CONTRIBUTION TO THE DISCUSSION

\author{
RAFAEL MOLL NOGUERA \\ Profesor Ayudante Doctor, Universidad de Valencia \\ https://orcid.org/0000-0002-7763-4621
}

Cómo citar este trabajo: Moll Noguera, R. (2022). La negociación colectiva en la función pública en Portugal y España: una aportación para el debate. Lex Social, Revista De Derechos Sociales, 12 (1), pp. 298-323. https://doi.org/10.46661/lexsocial.6400

\section{RESUMEN}

La regulación del derecho a la negociación colectiva en la función pública constituye la mejor referencia para comparar el régimen jurídico de los trabajadores al servicio de la Administración pública entre Portugal y España. A través de una cartografía jurídica detallada, se pretende descubrir cuáles son los patrones comunes y las divergencias presentes a fin de ofrecer una visión panorámica que permitan, en su caso, enriquecer el debate de una eventual reforma legislativa. Se pondrá de manifiesto mediante el análisis de cada una de las dimensiones que configuran la negociación colectiva, que el modelo español resulta más flexible y ágil que el portugués.

Palabras ClaVe: comparación, negociación colectiva, administración pública, funcionarios, personal laboral.

\section{(cc) BY-NC-SA}




\begin{abstract}
The regulation of the right to collective bargaining in the public function constitutes the best reference to compare the legal regime of workers in the service of the public administration between Portugal and Spain. Through a detailed legal cartography, the aim is to discover which are the common patterns and the divergences present in order to offer a panoramic vision that will allow, where appropriate, to enrich the debate on a possible legislative reform. Through the analysis of each of the dimensions that make up collective bargaining, it will be shown that the Spanish model is more flexible and agile than the Portuguese one.
\end{abstract}

KEYWORDS: comparison, collective bargaining, public administration, officials, labour staff.

SUMARIO

\title{
I. Introducción
}

II. Perspectiva subjetiva

1. Modalidades del derecho a la negociación colectiva

2. Sujetos legitimados y unidades de negociación

3. Ámbito subjetivo de la negociación laboral

III. Perspectiva material

1. Contenidos negociables

2. Concurrencia conflictiva y reglas de solución

3. Inaplicación convencional

IV. Perspectiva temporal: vigencia y régimen de ultraactividad

$V$. Perspectiva formal: procedimiento y principios informadores

VI. Conclusiones

Bibliografía 


\section{Introducción}

La negociación colectiva es uno de los derechos laborales cuyo análisis por parte de la doctrina resulta más complejo por su carácter multidimensional pero que constituye, sin duda, la piedra angular de protección en los sistemas de relaciones laborales avanzados, gracias al reconocimiento de un espacio propio y autónomo en favor de sus protagonistas para la fijación o mejora de las condiciones de trabajo.

En particular, esta complejidad aumenta si el foco lo ponemos sobre la función pública, dadas las singularidades y especialidades normativas que poseen los colectivos de trabajadores que la integran. En efecto, aunque la virtualidad del derecho a la negociación colectiva en la función pública se conserva, pues se dirige igualmente a la mejora de las condiciones laborales de los servidores públicos, no debe desconocerse que está fuertemente marcada por el hecho de que una las partes negociadoras es la propia Administración pública y por el interés general que esta debe preservarse y garantizarse en todo momento.

A diferencia de lo que ocurre con el derecho a la negociación colectiva en el ámbito privado, la que tiene lugar en el seno de las Administraciones públicas no suele aparecer ni explicarse en los temarios o manuales de las carreras universitarias, ni tampoco se sitúa en los debates públicos sobre futuras reformas legislativas, por lo que corre el riesgo de pasar desapercibida sin que se le preste la atención que merece.

Precisamente a efectos de enriquecer este análisis y conocer los actuales contornos legales de este derecho, la metodología del estudio comparado entre dos ordenamientos jurídicos vecinos se presenta como la más idónea al permitir, a la luz de las similitudes y diferencias entre ambos sistemas, tener una visión global de su conceptualización legal, al tiempo que se identifican posibles inspiraciones recíprocas de lege ferenda para el perfeccionamiento o mejora de ambas regulaciones.

En este sentido, en las páginas siguientes se pretende confrontar de forma sistemática la normativa sobre el derecho a la negociación colectiva en la función pública en Portugal y España, a través del estudio detallado de cada una de sus dimensiones. Se tratará de acentuar en todo momento los elementos comunes y divergentes entre ambos ordenamientos con el fin de que el lector obtenga una visión panorámica. Así pues, gracias a la realización de esta cartografía jurídica comparada, es posible ofrecer un análisis más crítico de la norma asentado en la originalidad de otro sistema legal.

\section{Perspectiva subjetiva}

\section{Modalidades del derecho a la negociación colectiva}

El derecho a la negociación colectiva del personal al servicio de la Administración pública en Portugal se encuentra fundamentalmente regulado en la Ley 35/2014, de 20 de junio, Ley General del Trabajo en la Función Pública (Lei Geral do Trabalho em funções Públicas, en adelante LTFP) y, en particular, en el Título II de la referida ley. Así, al igual 
que ocurre en España en el RD 5/2015, de 30 de octubre, por el que se aprueba el texto refundido de la Ley del Estatuto del Empleado Público (en adelante, EBEP), es la propia ley estatutaria la que determina los términos en los que debe ejercerse este derecho por parte de los trabajadores al servicio público.

En ambos países, a la hora de analizar el régimen jurídico de los empleados públicos debe partirse de una diversificación de regímenes jurídicos general en función del vínculo que mantenga el trabajador con la Administración pública correspondiente ${ }^{1}$. En efecto, por un lado, existe un conjunto de reglas enfocadas de forma exclusiva al personal funcionarial o "trabalhadores em funções públicas", y otras previsiones diferenciadas para los "trabalhadores com contrato de trabalho em funções públicas", el equivalente el personal laboral en el ordenamiento jurídico español. Esta dualidad de regímenes jurídicos global se materializa también en lo que a la regulación del derecho a la negociación colectiva se refiere. Así, serán diferentes las previsiones normativas en materia de legitimación negociadora, tipología de acuerdos, alcance subjetivo del acuerdo, procedimiento, vigencia del acuerdo, etc.

Antes de prestar atención a la regulación concreta de las instituciones más relevantes que conforman la negociación colectiva en ambos ordenamientos jurídicos, resulta preciso aclarar que la intensidad de este derecho es menor, en ambos países, cuando es ejercido por el personal funcionarial. La razón no es otra que el necesario intervencionismo del Gobierno para la culminación del proceso de negociación en forma de aprobación expresa $\mathrm{y}$ formal.

Así, en el ordenamiento portugués, aunque las partes pueden negociar sobre materias con incidencia en sus condiciones laborales, deben trasladar posteriormente dichos acuerdos a los órganos legislativos o gubernativos competentes para que ellos lo materialicen en actos legislativos o reglamentarios aplicables a estos determinados trabajadores. Eso sí, de conformidad con lo previsto en el art. 354 LTFP, de alcanzarse acuerdo entre las partes, el Gobierno competente debe adoptar obligatoriamente las medidas legislativas o administrativas adecuadas para su integral y exacto cumplimiento en el plazo máximo de 180 días. En aquellos casos en los que el gobierno carezca de la competencia suficiente, deberá someterlo a la Asamblea legislativa en el plazo máximo de 45 días.

A pesar de esta limitación formal, la doctrina portuguesa mantiene que sí constituye una manifestación de este derecho suficiente para tutelar la posición y los intereses de este colectivo, al tiempo que rechaza que se confunda con el derecho general de participación de los trabajadores en la elaboración de la legislación laboral regulado en los arts. 15 y

\footnotetext{
${ }^{1}$ VASCONCELOS ALBUQUERQUE SOUSA, Nuno José, “A reforma do emprego público em Portugal e Espanha”, en F. Liberal Fernandes y M. Regina Redinha, Transformações recentes do Direito do Trabalho Ibérico, Porto: UP; 2016, pp. 253-269

2 Debe advertirse, si quiera de modo introductorio, que no existe una correspondencia plena entre la dualidad de regímenes del personal al servicio de la Administración en el caso portugués y el español, dualidad, entre otras razones porque en Portugal la regla general es la contratación laboral (arts. 7 y 8 LTFP) o porque en ambas categorías existe el contrato de duración determinada.
} 
16 LTFP $^{3}$. En este sentido, aunque en estos dos preceptos se contempla un elenco de materias coincidentes con las previstas en el art. $350 \mathrm{LTFP}^{4}$, responden a finalidades distintas, encuentran procedimientos diferenciados ${ }^{5} \mathrm{y}$, sobre todo, sus resultados no son equiparables, en la medida en la que de la mera consulta no surge la obligatoriedad de trasladar el eventual acuerdo alcanzado a la norma que se apruebe.

De forma similar, en España también se vuelve precisa la ratificación gubernativa o la iniciativa legislativa en reserva de ley en los acuerdos colectivos de funcionarios, que no son aplicables sin este acto jurídico o ley. Sin embargo, existe una importante diferencia, ya que en España la Administración gubernativa decide si los aprueba o los incorpora al proyecto de ley correspondiente o no, tanto por razones de legalidad como de oportunidad a tenor del art. 38.3 in fine $\mathrm{EBEP}^{6}$. La consecuencia de esta negativa no es otra que la posibilidad de renegociación de las materias tratadas en el plazo de un mes si así lo solicita la mayoría de una de las partes, fijándose en última instancia las condiciones de trabajo de los funcionarios por los órganos de gobierno de las Administraciones públicas afectadas (art. 38.7 EBEP) ${ }^{7}$.

Ahora bien, el Gobierno competente español solamente puede decidir si lo aprueba o no ${ }^{8}$, es decir, ha de respetar necesariamente el contenido del acuerdo alcanzado por las partes en sus propios términos ${ }^{9}$. Asimismo, debe someterse con carácter previo, obligatorio y con suficiente antelación a la mesa de negociación competente para que se desarrolle el derecho a la negociación colectiva ${ }^{10}$. Por estas razones puede concluirse que, pese a esta limitación formal ${ }^{11}$, la negociación colectiva funcionarial en España también se diferencia del derecho general a consulta.

\footnotetext{
${ }^{3}$ LUCAS PIRES, Miguel, Lei Geral do Trabalho em funções Públicas, Coimbra: Almedina, 2016, p. 73. En contra, Alburquerque Sousa, Nuno Vasconcelos, "A reforma do emprego público em Portugal", Questões Laborais, num. 45, pág. 241.

${ }^{4}$ Constitución, modificación y extinción del vínculo laboral; reclutamiento y selección; tiempo de trabajo; vacaciones, ausencias y excedencias; retribución; formación profesional; seguridad y salud en el trabajo; régimen disciplinar; movilidad; evaluación del desempeño; derechos colectivos; régimen de protección social; y acción social complementaria

${ }^{5}$ El procedimiento legal para materializar este derecho de participación contempla que las asambleas legislativas o los gobiernos regionales competentes puedan discutir y votar un proyecto de norma, previamente consensuado por las comisiones de trabajadores y las asociaciones sindicales, remitiéndose en todo lo demás a la regulación prevista en el Codigo do Trabalho (en adelante CT, arts. 472-475).

${ }^{6}$ SSTS (CA) de 7 de octubre de 2014 (rec. 1650/2013) y de 30 de marzo de 2015 (rec. 1718/2014).

${ }^{7}$ ROQUETA BUJ, Remedios, Derecho del Empleo Público, Valencia: Tirant lo Blanch, 2020, p. 589.

${ }^{8}$ Idem.

${ }^{9}$ ALFONSO MELLADO, Carlos L., Los derechos colectivos de los empleados públicos en el Estatuto Básico, Albacete: Bomarzo, 2008, pp. 43 y 49.

${ }^{10}$ Ibidem, p. 48.

${ }^{11}$ En cuanto a este recorte formal en la intensidad del derecho a la negociación colectiva que sufren los funcionarios españoles, debe traerse a colación el difícil y tardío reconocimiento que el mismo tuvo, al no encajar ni derivar directamente del art. 37.1 de la Constitución española (en adelante CE) (SSTC 57/1982; 85/2001). En España, la negociación colectiva de funcionarios tuvo una mención expresa en la DA $2^{\text {a }}$ de la Ley Orgánica 11/1985 de libertad sindical, hasta su definitiva articulación en el capítulo III de la Ley 9/1987 de órganos de representación, determinación de condiciones de trabajo y participación del personal al servicio de las Administraciones públicas (LORAP), luego reformado por la Ley 9/1990 y la Ley 21/2006, concluyendo el proceso en la Ley 7/2007 del Estatuto Básico del Empleo Público, refundida ahora en el RD Legislativo 5/2015, de 30 de octubre.
} 
Lo que ocurre, en realidad, es que dichos acuerdos versan sobre materias competencia de los órganos de Gobierno de las diferentes Administraciones públicas, y que incluso pueden requerir la adopción de una norma con rango de ley. En definitiva, este acto posterior de aprobación de la negociación se justifica por la necesidad de que el acuerdo alcanzado entre la Administración pública y los representantes sindicales sea aprobado por el órgano competente y revista la forma adecuada para su validez. Este acto de ratificación no altera su naturaleza jurídica, gozando de la misma que el EBEP reconoce a los frutos de la negociación colectiva, esto es, eficacia normativa y general en su ámbito de aplicación y que, antes de su aprobación, no es sino un preacuerdo, sujeto a ratificación ${ }^{12}$.

Otra diferencia importante es que en el modelo español, y a diferencia de lo que ocurre en Portugal, no todos los acuerdos que se alcancen entre los representantes de los funcionarios y la Administración pública en cuestión requieren de este ratificación gubernativa o legislativa posterior, sino, como acaba de señalarse, solamente los que afecten a competencias propias de estos poderes y deban ser aprobados según el procedimiento legal previsto. Junto con estos acuerdos, cohabitan los Pactos que, al igual que los acuerdos, son fruto de la negociación colectiva en el ámbito funcionarial, por lo que su finalidad es la misma, la de regular las condiciones de trabajo. A tenor del art. 38.2 EBEP, la diferencia estriba en que versan sobre materias que se corresponden estrictamente con el ámbito competencial del órgano administrativo que los suscribe, sin que puedan afectar a las materias competencia de los órganos de gobierno del Estado, la Comunidad Autónomas o las Entidades Locales, pues ese es el terreno vedado de los Acuerdos. Es cierto que la virtualidad material de estos Pactos será menor que la de los Acuerdos, por cuanto que la mayor parte de las competencias sobre regulación de las condiciones de trabajo de los funcionarios públicos está reservada a los órganos de gobierno o requieren una ley para su aprobación. En todo caso, comparten naturaleza jurídica, teniendo eficacia normativa y general en el ámbito determinado por los negociadores.

Una vez aclarada esta importante diferencia que se repite, con los matices vistos, tanto en Portugal como en España en cuanto a la configuración del derecho a la negociación colectiva funcionarial, estamos en disposición de adentrarnos en el análisis de las principales instituciones que configuran este derecho. Para ello, es preciso recordar, como se decía al principio, que en ambos países se parte de una dualidad de regímenes jurídicos preexistente respecto de la regulación del derecho a la negociación colectiva. Así, por un lado, la LTFP dedica los arts. 347 a 349 a establecer disposiciones comunes; los arts. 350 a 354 para la negociación colectiva de los trabajadores "em funções públicas"; y los arts. 355 a 378 para los trabajadores "com contrato de trabalho". Por otro lado, los arts. 32 a 28 y la DA 12 a del EBEP regulan la negociación colectiva del personal funcionarial y se remite en el art. 32 EBEP a la legislación laboral respecto del personal laboral, sin

${ }^{12}$ ALFONSO MELLADO, Carlos L., Los derechos colectivos de los empleados... cit., pp. 41 y 43. 
perjuicio de los preceptos que expresamente les resulten aplicables del capítulo IV del EBEP.

\section{Sujetos legitimados y unidades de negociación}

En coherencia con la dualidad de regímenes vista en ambos países, empecemos pues por los sujetos legitimados para ejercer este derecho en el ámbito funcionarial en Portugal. De partida, el art. 347 LTFP limita los sujetos titulares de este derecho en el ámbito de la función pública, al igual que en el caso español y en sintonía con lo previsto en el art. 33.1 EBEP, a las asociaciones sindicales previamente registradas. De este modo, el art. 349 LTFP especifica y enumera un nutrido y variado conjunto de actores sindicales.

En Portugal están legitimadas las confederaciones sindicales presentes en la Comisión Permanente de Concertación Social; las asociaciones sindicales con un número de trabajadores afiliados que corresponda, al menos, al $5 \%$ del número total de trabajadores funcionarios; las asociaciones sindicales que representen a trabajadores de todas las administraciones públicas en la administración estatal siempre que el número de trabajadores afiliados alcance, al menos, el $2.5 \%$ de trabajadores funcionarios; en relación con la negociación colectiva sectorial, teniendo en cuenta las especificidades de la carrera profesional de cada sector, estarán legitimadas las asociaciones sindicales presentes en la Comisión Permanente de Concertación Social y las asociaciones sindicales que representen, al menos, al $5 \%$ del número total de trabajadores integrados en la carrera especial en cuestión.

En España, la representación de los funcionarios españoles en las mesas de negociación corresponde en exclusiva también a las organizaciones sindicales contempladas en el art. 33.1 EBEP. Así, y por remisión a los arts. 6.2, 7.1 y 7.2 de la Ley Orgánica de Libertad Sindical, solamente están legitimados los sindicatos más representativos y representativos, debiendo existir correspondencia entre el ámbito de representación de la organización sindical y el ámbito convencional a negociar.

Como se observa, aunque ambos países comparten el modelo sindical ${ }^{13}$, puede observarse una diferencia relevante por lo que se refiere a los sujetos legitimados por parte de los funcionarios portugueses y españoles, que pasa por el requisito legal de representatividad. En efecto, mientras que en Portugal esta exigencia se mide en el número de trabajadores afiliados al sindicato firmante, en España se calcula sobre el número de representantes electos en los órganos de representación por el sindicato en cuestión. Ello explica, a su vez, los diferentes umbrales de representatividad exigidos: en el ordenamiento luso basta con el 5 o el 2,5\%; en el caso español la representatividad mínima pasa por haber obtenido el $10 \%$ del total de delegados de personal o delegados en juntas (mayor representatividad estatal ex arts. 33.1 EBEP y 6.1 Ley Orgánica de Libertad Sindical, en adelante LOLS);

\footnotetext{
${ }^{13}$ Debe significarse que esta preferencia en Portugal no es exclusiva para el sector público, pues el modelo sindical también opera con exclusividad en el sector privado, al reservase el derecho de negociación colectiva a las asociaciones sindicales a tenor del art. 491 y 423 CT.
} 
un $15 \%$ del total de delegados y que se cuente con un mínimo de 1500 representantes en el caso autonómico (mayor representatividad autonómica ex arts. 33.1 EBEP y 7.1 LOLS); o bien el $10 \%$ de representantes en las unidades electorales comprendidas en el ámbito específico de su constitución para obtener la condición de representativo (arts. 33.1 EBEP y 7.2 LOLS). A ello habría que sumar la exigencia prevista en el art. 35.1 EBEP en virtud de la cual los sindicatos sentados en la mesa han de representar, como mínimo, a la mayoría absoluta de los representantes de los funcionarios en el ámbito de que se trate, debiendo incluso acreditarse la representatividad de cada organización sindical mediante el certificado de la oficina pública de registro cada dos años.

En definitiva, se desprende que en el modelo luso la representatividad para negociar es directa, al descansar sobre el número de trabajadores directamente afiliados al sindicato en cuestión; mientras que en el caso español, y por mimetización con el sistema privado de negociación colectiva, la representatividad se articula y se calcula indirectamente y de forma derivada de los resultados electorales a representantes en los órganos propio de representación. A mayor abundamiento, en el ordenamiento jurídico portugués no se prevé ningún otro requisito añadido de legitimación, pues el acuerdo que se alcance solo vinculará a los afiliados de las partes firmantes. Por el contrario, en el caso español, el legislador debe garantizar que el acuerdo suscrito esté negociado por una representación que hable en nombre, al menos, de la mayoría absoluta de los representantes de los funcionarios, pues dicho acuerdo está dotado de eficacia personal general, afectando a todos el personal dentro de su ámbito de aplicación, esté o no afiliado.

Una vez vistos cuáles son los sujetos legitimados en el ámbito funcionarial, y antes de pasar al análisis de los sujetos negociadores del personal laboral, debemos resolver la incógnita de cuántas unidades de negociación es posible encontrarse en cada modelo, o dicho de otro modo, cuantos negociadores legitimados pueden ejercer el derecho a la negociación colectiva al mismo tiempo. Así, puesto el foco en la estructura de la negociación colectiva, en el ordenamiento luso es posible diferenciar una negociación colectiva general o especial/profesional en función del alcance objetivo y territorial de la propuesta resultante del proceso de negociación que debe existir entre los sindicatos y las administraciones implicadas, cuyos procedimientos y formas de articulación se explicarán más adelante.

Este esquema básico contrasta con la estructura de la negociación colectiva en España, que probablemente es algo más rígida, en la medida en la que los arts. 34 y 36 EBEP predeterminan legalmente cuáles son las unidades de negociación de los funcionarios, en forma de Mesas generales y sectoriales, a las que concurren los titulares del derecho a negociar. De este modo, nos encontramos con una Mesa General de todas las Administraciones Públicas (art. 36.1 EBEP); una Mesa General en la Administración del Estado (art. 34.1 EBEP); una Mesa General en cada Comunidad Autónoma (art. 34.1 EBEP); una Mesa General en cada entidad local o ámbito supramunicipal (art. 34.1 y 34.2 EBEP); a las que habría que añadir mesas sectoriales por acuerdo de las mesas generales en atención a las condiciones específicas de trabajo de las organizaciones administrativas 
afectadas o a las peculiaridades de sectores concretos de funcionarios y a su número (art. 34.4 EBEP); y por último, mesas sectoriales de personal docente no universitario; de personal de Administración de Justicia; y de personal estatutario de los servicios de Salud (DA $12^{\text {a }}$ EBEP). Esta organización inicial se complica por cuanto las Comunidades Autónomas pueden configurar legalmente nuevas mesas sectoriales en el ámbito público de sus competencias sin necesidad de acuerdo de la mesa general ${ }^{14}$.

La relación entre las mesas generales y las sectoriales juega en favor de las primeras, de tal modo que las sectoriales podrán abordar aquellas cuestiones no acordadas por la mesa general o sobre las que haya un reenvío o delegación previa, siempre respetando la distribución de competencias entre las distintas administraciones afectadas.

Además de este enjambre de unidades de negociación, en España existen Mesas comunes de negociación colectiva de funcionarios y del personal laboral que van más allá de la confluencia de negociaciones por separado en un mismo nivel. El art. 36.3 EBEP reconoce la convergencia legal entre ambas negociaciones con el fin de poder negociar todas aquellas materias y condiciones de trabajo comunes al personal funcionarial, estatutario y laboral de cada Administración pública. La norma prevé la necesidad de que se conforme una Mesa común en la Administración General del Estado, en cada una de las comunidades autónomas y en las entidades locales. El acuerdo resultante, según prevé el art. 38.8 EBEP, tendrá la doble naturaleza de acuerdo o pacto para los funcionarios y de acuerdo para materias concretas para el personal laboral ex art. 83 ET. Resultan de aplicación a estas Mesas Generales los criterios de legitimación previstos para la Mesa General de Negociación de las Administraciones Públicas (art. 36.1 EBEP, es decir, mayor representatividad), tomando en consideración en cada caso los resultados obtenidos en las elecciones a los órganos de representación del personal funcionario y laboral del correspondiente ámbito de representación. No obstante, de no alcanzarse la condición de más representativa, también están legitimadas las organizaciones sindicales que hubieran obtenido el 10 por 100 de los representantes a personal funcionario o personal laboral en el ámbito correspondiente a la Mesa de que se trate y que formen parte de la Mesa General de Negociación de las Administraciones Públicas ${ }^{15}$.

Si nos adentramos en la regulación del derecho a la negociación colectiva del personal laboral o "trabajadores contratados" según terminología lusa, debemos partir de la idea de que en ambos países estos trabajadores sí tienen reconocido el derecho a la negociación colectiva en su máxima expresión, esto es, poder celebrar convenios colectivos o "instrumentos de regulamentação colectiva convencional". En efecto, de conformidad con las fuentes aplicables al personal al servicio de la Administración pública portuguesa,

\footnotetext{
${ }^{14}$ LAHERA FORTEZA, Jesús, "La negociación colectiva del personal laboral de las administraciones públicas"; en Ángel Blasco Pellicer y Mercedes López Balaguer (Dirs.), Las relaciones laborales en el Sector Público, Valencia: Tirant lo Blanch, 2019, p. 998.

${ }^{15}$ Esta previsión es importante por cuanto en la Mesa General del Estado, los sindicatos sectoriales que acrediten un $10 \%$ de representantes estatales no tienen derecho a participar, pues su ámbito funcional y territorial de representación es inferior al ámbito de la mesa negocial según se desprende del art. 36.1 segundo párrafo EBEP.
} 
recogidas en el art. 13.4 LTFP, solamente los convenios colectivos resultan aplicables al personal contratado, excluyendo por tanto al personal "nomenado". Ello se explica por la marcada concepción de naturaleza estatutaria y unilateral, que no contractual, del vínculo de estos últimos con la Administración ${ }^{16}$.

A fin de explicar los sujetos legitimados en el modelo portugués, es preciso aclarar que en su ordenamiento jurídico es posible encontrarse con diferentes instrumentos de regulación colectiva convencional, a saber: el acuerdo colectivo de trabajo; el acuerdo de adhesión; y la decisión de arbitraje voluntaria. Siendo el primero de ellos el principal y más importante, debemos diferenciar los dos tipos de acuerdo colectivo de trabajo existentes: el acuerdo colectivo de carrera, el cual es aplicable en el ámbito de una carrera profesional determinada (especial) o de un conjunto de carreras (general), independientemente del órgano o servicio donde el trabajador preste sus servicios (art. 13.6 LFTP); y el acuerdo colectivo de empleador público, el cual solo se aplicará en el ámbito del órgano o servicio donde el trabajador ejerza sus funciones (art. 13.7 LFTP).

En coherencia con lo anterior, y desde el punto de vista subjetivo, se diferencian hasta tres legitimaciones. En primer lugar, si el convenio colectivo es de carrera general, estarán legitimadas, en representación de los trabajadores, las asociaciones sindicales que ostenten legitimación para llevar a cabo la negociación funcionarial y, por el lado del empleador, los miembros del gobierno responsables de las áreas económicas y de la administración pública. Asimismo, estarán legitimadas las asociaciones sindicales que presenten una única propuesta de celebración o de revisión de convenio y que, en su conjunto, cumplan los criterios del art. 349.1 b) y c) LTFP (5\% de los trabajadores y el $2,5 \%$ de todas las administraciones).

En segundo lugar, para negociar acuerdos colectivos de carrera profesional especial, por el lado obrero, estarán legitimadas las asociaciones sindicales, las confederaciones sindicales presentes en la Comisión Permanente de Concertación Social y las asociaciones sindicales que representen, al menos, al 5\% del número total de trabajadores integrados en la carrera especial en cuestión. Por el lado empleador, lo estarán lo miembros del gobierno responsables de las áreas económicas y de administración pública y otros miembros del gobierno interesados atendiendo a la carrera especifica de los acuerdos.

En tercer lugar, aparecen los "acordos colectivos de empregador público", que hacen referencia a otras administraciones que gozan de autonomía frente al Estado, como son los Ayuntamientos, Universidades, entidades independientes o servicios administrativos concretos. En estos casos, la legitimación obrera es más amplia al reconocerla a todas las asociaciones sindicales representativas de los trabajadores en cuestión. Mayor dificultad presenta la legitimación por parte del empleador, pues parece exigirse la firma del Gobierno estatal para su correcta celebración, si bien el Tribunal Constitucional

${ }^{16}$ PEDRO MADEIRA DE, Brito, "O reconhecimento legal do direito à contratação à consolidação", Questões Laborais, num. 45, 2014, pp. 329 e segs. 
portugués, en el Acordo $n^{\circ}$ 494/2015 de 7 de Outubro entendió inconstitucional la potestad concedida al gobierno de firmar acuerdos colectivos en el ámbito local por violación del principio de autonomía local, sin perjuicio del poder de supervisión y verificación de que los acuerdos alcanzados respeten la legalidad vigente.

En el caso español, el personal laboral al servicio de las Administraciones públicas puede ejercer el derecho a la negociación colectiva en similares términos que en el ámbito privado, remitiéndose, de hecho, el art. 32.1 EBEP a la legislación laboral, sin perjuicio de los preceptos que expresamente resulten de aplicación del EBEP. En consecuencia, y por lo que ahora interesa, estarán legitimados los mismos sujetos que los contemplados en los arts. 87 y 88 del ET, de tal suerte que si el ámbito en el que se desarrolla la negociación es superior a una única administración regirán, en principio, las reglas para la negociación de convenios supraempresariales; mientras que si el ámbito afecta solamente a una administración se aplicarán las previsiones para la unidad negociadora de empresa. En ambos casos, la legitimación del personal laboral abraza igualmente la representación unitaria de los trabajadores, amén de la sindical.

Debe significarse que entre las previsiones directamente aplicables del EBEP a la negociación del personal laboral se encuentra la necesidad de cobertura presupuestaria según el art. 21, lo que se traduce, por un lado, en la limitación retributiva fijada a nivel estatal en las sucesivas leyes de presupuestos y, por otro lado, en la autorización de la masa salarial que debe solicitarse al Ministerio de Hacienda u organismo autonómico equivalente y el informe favorable sobre el proyecto del convenio a emitir por el Ministerio de Hacienda y de Administraciones Públicas conjuntamente en la Comisión interministerial de Retribuciones u organismos autonómicos equivalentes con carácter previo a su acuerdo o firma ${ }^{17}$. Este control vertical del gasto se asemeja al poder de supervisión y verificación del Gobierno luso respecto a las unidades inferiores.

\section{3. Ámbito subjetivo de la negociación laboral}

Si profundizamos en la dimensión subjetiva de la negociación colectiva laboral, surge la incógnita sobre cuál es el alcance personal de estos convenios colectivos. Como ya se ha adelantado, en Portugal, al igual que ocurre en la negociación colectiva en el ámbito privado, los convenios colectivos carecen de eficacia personal general o erga omnes, vinculando solamente a los firmantes del acuerdo, durante el tiempo de vigencia del convenio, incluso en caso de desafiliación ${ }^{18}$. Así, el art. 370 LTFP contempla que los convenios colectivos del personal "contratado" solo resulten aplicables a los trabajadores afiliados a la asociación sindical firmante así como a los miembros de esta en caso de pertenecer a la federación o confederación sindical firmante.

\footnotetext{
17 Arts. 18 y 32.4 de la Ley 11/2020, de 30 de diciembre, de Presupuestos Generales del Estado para el año 2021 que expresamente en el punto ocho establece que los acuerdos, convenios o pactos que impliquen crecimientos retributivos superiores a los fijados en dicho artículo 18 devendrán inaplicables.

${ }^{18}$ Salvo en los casos de convenios sin fecha de vigencia, pues el trabajador estará sujeto al convenio en por un periodo de un año a partir de la desafiliación según el art. 371.1 LTFP
} 
Ahora bien, y a diferencia de lo que ocurre en las relaciones laborales privadas (art. 496 del Codigo do Trabalho, en adelante CT), el art. 370.3 LTFP contempla una especie de extensión automática cuyo resultado es muy similar al de la eficacia general en España, por cuanto el convenio tendrá efectos también sobre el resto de trabajadores no afiliados siempre que no medie oposición expresa, mediante escrito dirigido a la Administración empleadora en el plazo de 15 días desde su entrada en vigor, bien por parte del propio trabajador, bien por otra asociación sindical legitimada para celebrar un convenio colectivo para sus afiliados. Es más, la norma prevé que, en caso de que resulten aplicables diferentes convenios colectivos, el trabajador no afiliado deberá indicar a cuál se acoge, primando, en caso de silencio, el convenio por el que se rija el mayor número de trabajadores.

Como se observa, en Portugal no rige el principio de unidad de convenio, de tal modo que la Administración pública deberá aplicar tantos convenios como hubiera negociado o dentro de los cuales se encuentre. De hecho, esta diversidad de convenios aplicables se hace evidente en el momento en el que el trabajador no afiliado es quien tiene la facultad de decidir unilateralmente cuál debe el ser el convenio, entre los vigentes en la Administración para la que presta servicios, que regirá su relación laboral. La previsión de extensión automática desconocida en el ordenamiento jurídico privado portugués conjugada con la importante facultad concedida al trabajador individual para que decida el convenio aplicable ha llevado a parte de la doctrina a sostener que puede provocar una desafiliación sindical y un menoscabo en la representatividad de las asociaciones sindicales ${ }^{19}$.

No obstante, esta facultad no es absoluta y encuentra un importante obstáculo en la eventual decisión que pudiera adoptar el sindicato no firmante. A pesar de que el trabajador manifieste expresamente su decisión de regirse por un determinado convenio vigente, se impondrá la oposición del sindicato al que se encuentra afiliado el mismo, bastando para ejercer este veto que tenga interés y esté legitimado. Así, en última instancia, la aplicación de un convenio colectivo a trabajadores afiliados a un sindicato no firmante depende del beneplácito de este último ${ }^{20}$.

A mayor abundamiento, la norma portuguesa, en su art. 372 LFTP, tomando de nuevo como punto de gravedad al trabajador concreto, prevé que en aquellos supuestos en los que se cambie el destino por razones organizativas entre administraciones, se deberá mantener el convenio colectivo de origen hasta perder su vigencia y, en todo caso, al menos 12 meses, salvo que entre en vigor un nuevo convenio en la administración de destino. Idéntica solución se prevé si el lugar de destino es una entidad pública empresarial o "entidades privadas sob qualquer forma".

${ }^{19}$ DE OLIVEIRA CORREIA, André, "Os , não tão) novos horários de trabalho dos trabalhadores das carreiras gerais: perdidos entre a lei e instrumentos de regulamentação coletiva de trabalho", Questões Laborais, num. 45, 2014, p. 372.

${ }^{20}$ LUCAS PIRES, Miguel, Lei Geral do Trabalho ...cit., p. 424. 
En contraste con este complejo escenario, la solución española es más sencilla, al brindarse eficacia general a los convenios negociados por los sujetos que revisten la representatividad legal necesaria. Gracias a esta eficacia erga omnes la aplicación del convenio no descansa en el dato afiliativo y por tanto se aplicará a todos los trabajadores incluidos en su ámbito de aplicación con independencia de que estos estén o no afiliados.

Dicho esto, aunque el art. 32.2 EBEP garantiza el cumplimiento de los convenios colectivos que afecten al personal laboral, hasta las SSTS de 6 de mayo de 2019 (recs. 4452/2017; 406/2018; 409/2018; 608/2018) existía cierta confusión en torno a si los convenios sectoriales del ámbito privado debían aplicarse al personal laboral al servicio de las Administraciones públicas, en la medida en la que estos afectaban y resultaban de aplicación automática a todos los trabajadores incluidos en el sector regulado por el convenio. El TS dio un importante giro a tu anterior doctrina para alcanzar la conclusión de que una Administración pública, sin convenio colectivo propio, no puede quedar afectada por lo dispuesto en un convenio sectorial del que no ha formado parte ni está representada por las asociaciones empresariales firmantes del mismo, aunque sus trabajadores pudieran quedar incluidos teóricamente en su campo de aplicación ${ }^{21}$.

\section{Perspectiva material}

\section{Contenidos negociables}

Si realizamos un análisis de las materias negociables en la función pública, empezando por el ordenamiento jurídico portugués, descubrimos, en primer lugar, que las materias sobre las que las partes pueden alcanzar un acuerdo son muy similares entre el personal funcionarial y el laboral al servicio de la Administración portuguesa, si bien encuentran una regulación separada, posiblemente porque en el primer supuesto el legislador está pensando más en acuerdos concretos que en convenios colectivos globales.

Así, el art. 350 LFTP prevé un conjunto de materias, coincidentes todas ellas con las contempladas en el art. 15 LFTP respecto a la participación de los trabajadores en la elaboración de la legislación laboral, como son la constitución, modificación y extinción del vínculo laboral; reclutamiento y selección; tiempo de trabajo; vacaciones, ausencias y excedencias; retribución; formación profesional; seguridad y salud en el trabajo; régimen disciplinar; movilidad; evaluación del desempeño; derechos colectivos; régimen de protección social; y acción social complementaria.

Aunque pudiera pensarse que se trata de un listado cerrado de materias, habida cuenta de la taxatividad en la redacción de la norma, si nos fijamos en el número dos del mismo precepto, encontramos tres materias expresamente excluidas del ámbito de la negociación, como son la cuestiones relativas a la estructura, atribuciones y competencias

\footnotetext{
${ }^{21}$ MOLL NOGUERA, Rafael, "La negociación colectiva del personal laboral de las Administraciones públicas y su exclusión del convenio sectorial", Trabajo y Derecho: nueva revista de actualidad y relaciones laborales, núm. 69, 2020, pp. 1-29.
} 
de la Administración pública. Así pues, es posible defender que, salvo estas tres materias, las partes son libres para alcanzar acuerdos sobre cualquier otra condición que integra el estatuto de los trabajadores con funciones públicas.

En contraste, las materias objeto de convenios colectivos negociados por el personal laboral portugués cuenta con una regulación más detallada. El art. 355 LFTP comienza señalando que solamente podrán regular las materias tasadas en dicho precepto, sin perjuicio de una mayor habilitación expresa por otros preceptos legales. Estas materias son el sistema retributivo; el sistema evaluativo del desempeño; los regímenes de duración y organización del tiempo de trabajo; la movilidad geográfica; y la acción social complementaria.

Como puede observarse, a diferencia de lo previsto para los trabajadores con funciones públicas, no son objeto de negociación la selección de trabajadores; la carrera profesional y la promoción; el calendario de festivos y descansos; la formación; el régimen disciplinario; ni los derechos colectivos.

Es posible encontrar otros preceptos que amplían este catálogo, por ejemplo, la seguridad, higiene y salud en el trabajo prevista en el art. 361.1 LFTP o la definición de los servicios mínimos y de los medios necesario para garantizarlos en caso de huelga en el art. 366.1.c) LFTP. Asimismo, se pueden encontrar preceptos que amplían este listado pero con limitaciones. Es el caso del art. 51 LFTP que permite fijar el periodo de prueba en los convenios colectivos, sin que quepa su eliminación o la fijación de indemnización durante dicho periodo. Otro ejemplo es el art. 77.1 LFTP que declara nulas las cláusulas incluidas en los convenios colectivos que perjudiquen el ejercicio del derecho al trabajo después de finalizar el vínculo con la administración, salvo que concurran las condiciones establecidas en el mismo.

Esta concepción tan limitada de la negociación colectiva para el personal laboral portugués choca con lo previsto en el art. $478 \mathrm{CT}$, pues en el sector privado las partes son libres para negociar cuantas condiciones laborales consideren oportunas, respetando, eso sí, el contenido imperativo de la ley y sin entrar a regular actividades económicas, especialmente el régimen fiscal, fijación de precios, etc., y sin poder dotar de eficacia retroactiva al contenido no pecuniario del acuerdo. Por tanto, a diferencia del ámbito privado, aquí la concepción ha sido la inversa: enumerar el conjunto de materias típicas o potenciales de negociación e, indirectamente, en relación con el resto de las condiciones, considerar que existe reserva de ley impidiendo su modificación por la vía negocial $^{22}$. A este respecto, la doctrina portuguesa se ha planteado la posible inconstitucionalidad de esta limitación material a la negociación colectiva, si bien se concluye que sí se respeta el contenido esencial ${ }^{23}$. En todo caso, se mimetizan los límites generales a la negociación referidos del sector privado: prohibición de la irretroactividad, de afectar a las reglas que disciplina la libre competencia empresarial y de contrariar la

\footnotetext{
22 LUCAS PIRES, Miguel, Lei Geral do Trabalho...cit., p. 407

${ }^{23}$ PEDRO MADEIRA DE, Brito, “O reconhecimento legal ...", cit., pp. 343 e 344.
} 
ley. Ahora bien, entre estos límites se aprecia una falta de correspondencia entre lo fijado para el sector privado en el art. $479 \mathrm{CT}$ y en el ámbito público en materia de igualdad y no discriminación, pues la LFTP no contempla una garantía antidiscriminatoria en el contenido del convenio. Es por ello por lo que la doctrina portuguesa defiende extender su aplicación al ámbito público ${ }^{24}$.

Por otro lado, al igual que se prevé en el art. 503 CT en el sector privado, el art. 377 LFTP contempla una limitación material importante en cuanto a la sucesión de convenios del personal laboral. Aunque se parte del principio de derogación total, de tal suerte que el convenio posterior deroga íntegramente al anterior, salvo en las materias expresamente reservadas por las partes negociadoras, la norma añade inmediatamente a continuación la prohibición de que la mera sucesión de regulaciones convencionales justifique una disminución de la protección global de los trabajadores. Por si hubiera alguna duda sobre el alcance de la prohibición de libre disposición, el precepto aclara en su párrafo tercero que solo es posible disminuir el nivel de protección de condiciones laborales determinadas si en el convenio nuevo consta de forma expresa que el mismo tiene un carácter "globalmente más favorable". Debe advertirse que esta previsión de intangibilidad material por sucesión de convenios no está prevista para el caso de los funcionarios portugueses.

Por su parte, al analizar el contenido negociable en España, también se parte de una regulación diferenciada según se trate del personal funcionarial o laboral. Así, respecto de los primeros, el art. 37.1 EBEP establece un listado muy amplio de materias a negociar, existiendo gran coincidencia (no necesariamente terminológica) con las mencionadas en el art. 350 LFTP: criterios generales en materia de acceso, carrera, provisión, sistemas de clasificación de puestos de trabajo, y planes e instrumentos de planificación de recursos humanos; los criterios generales sobre ofertas de empleo público; las referidas al calendario laboral, horarios, jornadas, vacaciones, permisos, movilidad funcional y geográfica, así como los criterios generales sobre la planificación estratégica de los recursos humanos, en aquellos aspectos que afecten a condiciones de trabajo de los empleados públicos; la determinación y aplicación de las retribuciones complementarias de los funcionarios, las que afecten a las condiciones de trabajo y a las retribuciones de los funcionarios, cuya regulación exija norma con rango de ley y la aplicación del incremento de las retribuciones del personal al servicio de las Administraciones Públicas que se establezca en la Ley de Presupuestos Generales del Estado y de las comunidades autónomas; los criterios generales de los planes y fondos para la formación y la promoción interna; las previsiones que así se establezcan en la normativa de prevención de riesgos laborales; los criterios y mecanismos generales en materia de evaluación del desempeño; las propuestas sobre derechos sindicales y de participación; los planes de Previsión Social Complementaria, criterios generales para la determinación de prestaciones sociales y pensiones de clases pasivas y los criterios generales de acción social.

${ }^{24}$ LUCAS PIRES, Miguel, Lei Geral do Trabalho...cit., p. 408. 
Ahora bien, y a diferencia de la norma portuguesa, el art. 37.1 EBEP no incluye en el listado de materias a negociar las normas que deben regir la constitución, modificación y la extinción de la relación estatutaria, ni tampoco el régimen disciplinario aplicable, pues su marco normativo debe hallarse en el Título VII EBEP y en las leyes de Función Pública dictadas en su desarrollo, escapando pues del objeto de la negociación colectiva.

De todos modos, al igual que ocurre en el caso luso, este amplio listado de materias de negociación pone de manifiesto que sobre cualquier condición profesional de los funcionarios es posible alcanzar un acuerdo, salvo las recogidas en el art. 37.2 EBEP al estar excluidas expresamente, como por ejemplo, los poderes de dirección y control propios de la relación jerárquica.

Por lo que se refiere al personal laboral español, el contenido de los convenios colectivos viene regulado por el art. $85 \mathrm{ET}$, que contempla un listado mínimo de materias que deben configurar el convenio final, respetando los límites legales aplicables igualmente en el ámbito privado (por ejemplo, deben tratarse de temas esencialmente laborales; la proscripción de la discriminación; la necesaria correspondencia subjetiva entre el ámbito del convenio y la representatividad de las partes; o la homogeneidad material). Junto a ellos, deben atenderse otros límites específicos al movernos en el terreno de lo público provenientes del EBEP y de la Constitución Española (en adelante CE), como son el principio de legalidad; el de cobertura presupuestaria; los principios de igualdad, mérito y capacidad en el acceso al empleo; la eficacia en la planificación y gestión de los recursos humanos; o la objetividad e imparcialidad en el servicio.

En todo caso, hay una importante diferencia con el modelo luso en cuanto a la intangibilidad de derechos convencionales, pues en España, se prevé expresamente, por un lado que los "acuerdos y pactos" del personal funcionarial que sucedan a otros anteriores los derogan en su integridad, salvo los aspectos que se acuerde mantener expresamente ex art. 38.13 EBEP; y por otro lado, el art. 85.4 ET aplicable al personal laboral contempla también que el convenio colectivo que sucede a uno anterior pueda disponer sobre los derechos reconocidos en aquel, aplicándose íntegramente lo regulado en el nuevo convenio.

\section{Concurrencia conflictiva y reglas de solución}

De entrada, como hasta ahora, cabe diferenciar las eventuales situaciones de concurrencia conflictiva entre el personal funcionarial y el personal laboral. Así, y por lo que se refiere al personal funcionarial, debe participarse de la idea de que esta situación de concurrencia conflictiva difícilmente podrá darse en Portugal en la medida en la que los acuerdos allí, como ya se sabe, carecen de eficacia personal general y todos los acuerdos resultantes de la negociación deben ser aprobados por el gobierno o poder legislativo competente. Del mismo modo, en España también es harto difícil que se materialice este conflicto, a tenor de la predeterminación de las unidades y mesas de negociación fijadas en la ley y la distribución y ordenación de contenido negociable entre ellas (arts. 34, 36, 38.9 y DA 12a 
EBEP), primando lo fijado en las mesas generales sobre las sectoriales. A ello debería añadir que el ámbito material de la negociación colectiva está condicionado, a su vez, por el reparto de competencias normativas en material funcionarial entre el Estado, las Comunidades Autónomas y las Entidades Locales determinado por el bloque de constitucionalidad.

Si atendemos al personal laboral, en el ordenamiento jurídico portugués los escenarios de concurrencia conflictiva entre convenios se presentan como difíciles ante la ausencia de eficacia erga omnes de los mismos. No obstante, sí pueden darse al existir dos tipos de convenios, los "acordos coletivos de carrera" y los "acordos coletivos de empregador público" 25 . Recuérdese que los primeros hacen referencia a aquellos convenios que se negocian dentro de una carrera o conjunto de carreras profesionales, independientemente del órgano o servicio en donde esos trabajadores prestan sus servicios (art. 13.6 LFTP); mientras que los segundos resultan aplicables a un órgano o servicio concreto en donde el trabajador ejerce sus funciones (art. 13.7 LFTP). La forma de articularse ambos tipos de convenios viene determinada por la ley en el art. 14 LFTP, en una especie de jerarquía material entre los mismos. Así, los convenios colectivos de carrera indicarán qué materias pueden ser reguladas por los acuerdos “de empregador público". En ausencia de él o en el caso de que no lo especifique, los acuerdos "de empregador público" solamente podrán regular las materias relativas a la seguridad y salud en el trabajo; la duración y organización del tiempo de trabajo, excluyendo los complementarios salariales. Mientras tanto, en España se deberá estar a las reglas de concurrencia conflictiva, que han de encontrarse, con carácter dispositivo, en el ET (art. 84) y en los eventuales acuerdos interprofesionales o convenios colectivos estatales o autonómicos que contemplen la estructura de la negociación colectiva y reglas específicas para conflictos de concurrencia entre convenios de distinto ámbito.

\section{Inaplicación convencional}

Por último, existe una diferencia importante entre ambos ordenamientos jurídicos relativa a la posibilidad de dejar de aplicar el régimen laboral previsto en los frutos de la negociación colectiva. En España, tanto para el personal funcionarial como para el personal laboral, se prevé en los arts. 38.10 y 32.2 EBEP respectivamente, la posibilidad de que los órganos de gobierno de las Administraciones públicas suspendan o modifiquen el cumplimiento de los convenios o acuerdos firmados por alteración sustancial de las circunstancias económicas de origen. Esta manifestación expresa del principio rebus sic stantibus en el orden laboral público fue introducida en la reforma operada por el Real Decreto-ley 20/2012, de 13 de julio de medidas para garantizar la estabilidad presupuestaria y de fomento de la competitividad, que vino a reconocer por vez primera la institución del descuelgue convencional en el ámbito público.

\footnotetext{
${ }^{25}$ Debe advertirse que de conformidad con el art. 13.3 LFTP los instrumentos de regulación colectiva convencional son los convenios colectivos, los acuerdos de adhesión y el laudo arbitral resultado de un arbitraje voluntario.
} 
Así pues, esta posibilidad se presenta como una excepción causal y finalista, al quedar restringida para aquellos casos en los que concurra una causa grave de interés público derivada de una alteración sustancial de las circunstancias económicas con el objetivo específico de salvaguardar el interés público. Entre las posibles causas, la norma aporta ejemplos, como la necesidad de reequilibrio de las cuentas públicas o asegurar la estabilidad presupuesta o la corrección del déficit público. Además se presenta como una medida limitada, pues el alcance de la suspensión o de la modificación debe ceñirse estrictamente a conseguir ese objetivo.

En fin, obsérvese que esta posibilidad de modificar o suspender el régimen convencional tanto para funcionarios como para trabajadores laborales en España es mucho más amplia que las previsiones en el ámbito privado (art. 82.3 ET) al no estar limitada las materias afectadas, ni exigirse si quiera una negociación previa con los representantes, al adoptarse el acuerdo de forma unilateral por el órgano de gobierno competente, si bien es cierto que las causas previstas son más reducidas, al no incluirse las razones técnicas, organizativas o técnicas que no se traducen en una alteración sustancial de las circunstancias económicas.

En Portugal, como se decía, no está prevista la institución de la inaplicación (tampoco en el ámbito privado), sin perjuicio de que sea posible, por acuerdo entre las partes, la revisión total o parcial del convenio antes de perder la vigencia original pactada. De hecho, se contempla un prolijo procedimiento de conciliación, mediación o incluso arbitraje (arts. 387 a 393 LFTP) para el caso que Administración pública empleadora inste la revisión del acuerdo, promoviendo y facilitando que las condiciones laborales puedan actualizarse a las nuevas y cambiantes circunstancias económicas del entorno.

En última instancia, al igual que ocurre en España, no puede olvidarse que los convenios, acuerdos o pactos que se suscriban entre las partes están fuertemente subordinados a las normas con rango de ley, por lo que el legislador competente podría acordar su suspensión o modificación sin necesidad de acudir al procedimiento del descuelgue. Es evidente que este último mecanismo es mucho más ágil al no requerir la aprobación de una norma con rango de ley para que el régimen convencional deje de aplicarse en sus términos originales, sino que es suficiente con su aprobación por parte del ejecutivo competente.

\section{Perspectiva temporal: vigencia y régimen de ultraactividad}

En relación con la vigencia de los acuerdos derivados de la negociación colectiva, cobra relevancia en ambos países de nuevo la diferencia entre la que se lleva a cabo por los funcionarios y el personal laboral.

Respecto de los primeros, la norma portuguesa no prevé nada expresamente, tal vez porque realmente no estamos ante un convenio colectivo sino ante una norma legal que recoge el acuerdo específico alcanzado por los negociadores. A lo sumo, es posible pensar que la vigencia de las condiciones laborales pactadas, en el caso de haberse previsto en la etapa de negociación, se puedan reflejar en la norma posterior. En España, la regulación 
de la duración de los Pactos y Acuerdos es única, a pesar de la diferencia notable en cuanto a su materialización formal. Así, el art. 34.8 EBEP exige que los mismo precisen su ámbito temporal, así como la forma, el plazo de preaviso y su denuncia. En este sentido, las partes negociadoras pueden establecer una duración determinada o indefinida, esto es, sin fecha máxima de vigencia. Ahora bien, debe ponerse en conexión con la vigencia de la norma que manifiesta el acuerdo, pues por ejemplo, en materia retributiva la vigencia de los Presupuestos Generales será anual necesariamente. Una vez concluida su duración, la vigencia de los pactos y acuerdos se producirá en los términos que se hubieran fijado (art. 38.12 EBEP), y en caso de no mediar denuncia por alguna de las partes legitimadas (legitimación plena) se irán prorrogando cada año, salvo que se acuerdo lo contrario (art. 38.11 EBEP).

Por lo que se refiere al personal laboral, la regulación de la duración de los convenios colectivos de este tipo de trabajadores en Portugal encuentra una notable coincidencia en lo esencial con lo previsto para el ámbito privado en los arts. 499 y ss. del CT. En este sentido, entrarán en vigor una vez sean publicados en el Diário da República. A diferencia de España, estos convenios colectivos no deben delimitar necesariamente su ámbito de aplicación temporal -que como mínimo será de un año- sino que perderán vigencia cuando se publique su "revogação" en el mismo Diario oficial. Es cierto, no obstante, que de conformidad con lo establecido en el art. 366.1 LFTP, el convenio colectivo deberá indicar el ámbito temporal del mismo, si bien lo limita a la regulación de la denuncia del mismo y al régimen de ultraactividad.

Dicha revocación puede ser el resultado de alcanzarse la fecha inicial prevista o de denunciarse por alguna de las partes. En el primer caso, superado el plazo de vigencia pactado, se seguirá aplicando en los términos que las partes hubieran acordado y, en su defecto, se prorrogará sucesivamente por periodos de un año. En el segundo caso, la denuncia no podrá afectar a un convenio vigente a tenor de la duración pactada, sino solamente podrá producirse durante los últimos tres meses antes de alcanzarse el plazo pactado o en aquellos convenios sin vigencia expresa una vez hayan transcurridos 10 meses desde su entrada en vigor.

En todo caso, se exige que la denuncia se acompañe de una propuesta negociadora para la revisión del convenio en cuestión, que marcará el inicio de un procedimiento de negociación nuevo. Este periodo destinado a alcanzar un nuevo convenio durará como máximo de 18 meses desde la denuncia, durante el cual el convenio seguirá aplicándose en los términos que las partes determinen y, en su defecto, solamente mantendrán vigencia las cláusulas relativas a la retribución y a la jornada laboral incorporadas a los contratos ${ }^{26}$. Asimismo, cualquiera de las partes puede instar, en caso de persistir el desacuerdo, el arbitraje obligatorio a partir del mes 12 desde la denuncia.

${ }^{26}$ Esa solución se separa ligeramente de lo previsto en el ámbito privado en donde el periodo de ultraactividad o "sobrevigencia" es de mínimo 12 meses. Cfr. Art. 501.3 CT. Asimismo, una vez superado esos 12 meses, la mantendrán, además de cláusulas relativas a la retribución y jornada, las que tienen que ver con la categoría y regímenes de protección social según el art. 501.8 CT. Por tanto, el régimen de ultraactividad en el ámbito privado es más corto, pero abarca más materias. 
En efecto, se prevé el mecanismo del arbitraje obligatorio, a instancia de cualquiera de las partes, como mecanismo extraordinario para desatascar las negociaciones, en paralelo, aunque de forma menos exigente a lo que se contempla también en el art. $510 \mathrm{CT}$ en el ámbito privado. Los arts. 375.4 y 382 y ss. LFTP prevén que un tribunal arbitral compuesto por 3 miembros, uno designado por cada parte y un tercero por estos dosdecida los términos del acuerdo. Dicho laudo tendrá el mismo valor que el convenio colectivo que hubieran alcanzado las partes.

En España, la duración del régimen convencional del personal laboral se halla regulada por remisión en los arts. 85 y 86 ET. Así pues, aparece como una obligación que las partes fijen el ámbito temporal del convenio, así como la forma, condiciones y plazo mínimo de denuncia del convenio. En cuanto a su terminación, es necesaria la denuncia para que este decaiga, pues de lo contrario seguirá aplicándose año a año (art. 86.3 ET), salvo que se pactara lo contrario. Una vez producida la denuncia, el convenio se aplicará según hubieran pactado las partes y, en defecto de este, seguirá aplicándose durante un año más, momento a partir del cual regirá el convenio colectivo de ámbito superior si lo hubiera (art. 86.3 in fine ET) . En caso de no existir este, se contractualizarán las condiciones de origen convencional, esto es, seguirán aplicándose las mismas condiciones laborales de origen por entenderse que han trasladado e integrado al contrato individual (STS de 23 de septiembre de 2015, rec. 209/2014).

Al igual que en el modelo portugués, se prevé la existencia de un arbitraje obligatorio activado por alguna de las partes, si bien este debe estar previsto en los acuerdos interprofesionales de ámbito estatal o autonómico ex art. 83 ET a fin de resolver la falta de acuerdo tras el transcurso del procedimiento de negociación.

\section{Perspectiva formal: procedimiento y principios informadores}

Para terminar con este análisis comparativo, resulta de interés fijarse brevemente en algunas de las características más importantes del procedimiento negociador. No se pretende pues, dar cuenta de todos y cada uno de los aspectos procedimentales que configuran formalmente el derecho a la negociación colectiva, sino que más bien se pretende ofrecer una visión global del conjunto de cada procedimiento a fin de confrontarlos entre sí.

En Portugal se parte del principio común de buena fe negocial, que deberá regir tanto el procedimiento de negociación funcionarial como el laboral. Este común denominador, que marcará y delimitará ambos procedimientos, está compuesto por un conjunto de comportamientos esperados por las partes que el propio art. 348 LFTP va concretando: el deber de responder con la máxima brevedad a las solicitudes de reunión y a las propuestas realizadas por la otra parte; el deber de asistir a las reuniones no solo destinadas a la negociación en sí, sino también a las enfocadas a la prevención o resolución de conflictos; y el derecho a solicitar a la otra parte la información necesaria e 
indispensable para un adecuado ejercicio de la negociación colectiva, incluyéndose estudios, informes técnicos o estadísticos no declarados confidenciales.

Debe advertirse que para la negociación colectiva de los trabajadores contratados, la norma añade que no se podrá denegar la puesta a disposición de las asociaciones sindicales legitimadas los informes sobre las actividades y servicios de los órganos administrativos $\mathrm{y}$, en todo caso, deberá informarse del número de trabajadores por categoría que se sitúen en el ámbito de aplicación del convenio que se negocia. En conexión con este principio, el art. 348.4 LFTP contempla otro específico para la negociación llevada a cabo por los "trabalhadores em funções públicas", cual es el de persecución de los intereses públicos desde una perspectiva global y común a todos los servicios y trabajadores según el art. 348.4 LFTP.

A partir de estos principios generales, cada tipo de negociación encuentra regulado separadamente el procedimiento a seguir: para los trabajadores en funciones públicas en los arts. 351 y siguientes LFTP y para los trabajadores con contrato se debe estar a los arts. 359 y siguientes LFTP.

Así, en el caso de la negociación de los funcionarios, la propia norma establece el momento exacto en el que debe iniciarse la negociación: el 1 de septiembre de cada año, momento en el que cualquiera de las dos partes podrá presentar una propuesta sobre las materias negociables, debiendo culminar necesariamente el procedimiento, en caso de alcanzarse acuerdo, antes de la votación final de la Ley de Presupuestos Generales en la Asamblea general portuguesa en los términos constitucionales previstos. No todos los acuerdos están sujetos a este marco temporal, pues las materias sin incidencia presupuestaria escapan de esta limitación, pudiendo negociarse en cualquier momento. De igual modo, la negociación colectiva sectorial podrá iniciarse en cualquier momento. Será potestad de las partes determinar el calendario de reuniones, si bien para su fijación deberá atenderse a la finalidad de alcanzar un acuerdo dentro del plazo legal.

A falta de acuerdo entre las partes, y habiendo terminado el periodo de negociación, es posible que las asociaciones sindicales fuercen, en una especie de último intento, el mantenimiento de la negociación. En efecto, a través de la denominada "negociación colectiva suplementaria", las secciones sindicales pueden mantener abierta por un periodo máximo de 15 días la negociación, esta vez, estando necesariamente representada la parte empleadora por los miembros del Gobierno si fuera general, o por el responsable del sector en cuestión. En último lugar, de persistir la falta de acuerdo, podrá ser el Gobierno competente el que adopte la decisión que entienda adecuada.

Por lo que se refiere al procedimiento de negociación del convenio colectivo por parte del personal laboral portugués, este mimetiza en gran parte las previsiones del Código do Trabalho para el sector privado. En efecto, puede hallarse un gran paralelismo entre los art. 359-369 LFTP y 485-487 CT. Así, este procedimiento se inicia con el envío por escrito de una propuesta por alguna de las dos partes, indicando la legitimidad que ostenta y si se trata de revisar un convenio en vigor (art. 359 LFTP y 486 CT). La parte receptora de la propuesta deberá dar una respuesta justificada en un plazo máximo de 30 días en 
relación con todas las cláusulas propuestas, aceptándolas, rechazándolas o haciendo una contrapropuesta. En caso de que no se produzca una respuesta en los términos indicados, se podrá instar a la conciliación (360 LFTP y 487 CT) y también el arbitraje obligatorio regulado en los arts. 382 y ss. LFTP. El procedimiento termina con el depósito del convenio, que deberá ir acompañado necesariamente de la acreditación de la representación que ostenta cada parte, salvo que en el plazo de 15 días desde la solicitud la autoridad administrativa competente (DDGAEP, Direção-Geral da Administração e do Emprego Público) decida no depositar por incumplir los requisitos legales.

Si nos fijamos en las reglas básicas del procedimiento negocial en el EBEP, se parte igualmente de una diversificación de reglas en función del tipo de empleado, así como de la consagración del principio de buena fe negocial (arts. 33.1 y $34.7 \mathrm{EBEP})^{27}$, junto con otros como son los de legalidad, cobertura presupuestaria, publicidad, transparencia, y obligatoriedad que, a pesar de estar previstos solamente para el procedimiento de negociación funcionarial, también alcanzan al procedimiento llevado a cabo por el personal laboral.

A partir de ahí, y en relación con el proceso negocial de los funcionarios, la norma prevé que se abra el mismo, en cada mesa, en la fecha que de común fijen las partes, y a falta de acuerdo, en un mes desde que una de las partes legitimadas lo promoviera (art. 34.7 EBEP). Tras la válida constitución de la mesa en los términos ya indicados más arriba, y una vez los pactos han sido celebrados y los acuerdos ratificados, se deberán remitir a la Oficina Pública que cada Administración competente determinada y la Autoridad respectiva ordenará su publicación en el Boletín Oficial que corresponda en función del ámbito territorial (art. 38.3 EBEP).

Al igual que en la normativa portuguesa, el art. 38.7 EBEP también prevé la conclusión sin acuerdo del procedimiento de negociación, debiéndose acudir a la mediación si lo solicita una de las partes negociadoras (art. 45.3 EBEP). A pesar de su carácter obligatorio, las propuestas de solución que ofrezca podrán ser libremente rechazadas por alguna de las partes. En segundo lugar, se contempla el arbitraje, aunque en este caso debe acordarse de común acuerdo por ambas partes y su laudo resultará vinculante . En última instancia, una vez agotados los procedimientos de solución extrajudicial de conflictos, el art. 38.7 EBEP contempla que los órganos de gobierno de las Administraciones públicas puedan establecer las condiciones de trabajo de los funcionarios de forma unilateral, respetándose en todo caso el régimen legal de ultraactividad.

En último lugar, respecto a los requisitos formales que acompañan a la negociación del personal laboral en España, se debe atender, de partida, a los principios generales referidos en el EBEP y que resultan igualmente aplicables a este tipo de trabajadores. A continuación, el procedimiento a seguir en las mesas laborales es el contemplado en el

\footnotetext{
${ }^{27}$ No obstante, y a diferencia de la norma portuguesa, el EBEP no dota de contenido propio a este principio. Debe acudirse a la jurisprudencia para delimitar el deber de negociar de buena fe, por ejemplo, la STS (CA) de 13 de abril de 1998 (rec. 353/1996),
} 
ET, sin perjuicio de que en la práctica se negocie en las diferentes mesas conjuntas siguiendo los trámites procedimentales previstos en el EBEP para la negociación funcionarial (art. 36.3 EBEP).

\section{Conclusiones}

Seguramente, si tuviera que recapitular el análisis comparativo realizado resaltaría que la regulación del derecho a la negociación colectiva en la función pública en Portugal y España resulta a grandes rasgos notablemente similar, si bien ambos ordenamientos jurídicos presentan importantes diferencias, que se sintetizan en la idea de la mayor flexibilidad del modelo español frente a la rigidez lusa.

En ambos países se dispone de una norma de referencia especial para la regulación de los derechos y deberes de los trabajadores públicos: la Ley 35/2014, de 20 de junio, Ley General del Trabajo en la Función Pública en Portugal, y el RD 5/2013, de 30 de octubre, por el que se aprueba el Estatuto del Empleado Público en España.

Por lo que se refiere en particular al derecho a la negociación colectiva, en ambas normas se contempla una diversificación de regímenes jurídicos en función del vínculo del trabajador: por un lado, unas previsiones específicas para los funcionarios y, por otro lado, otras previsiones expresas (en el caso portugués) o por remisión al Estatuto de los Trabajadores del ámbito privado (en el caso español) para el personal laboral. En este último sentido, tal y como se ha puesto de manifiesto en este trabajo, la técnica legislativa empleada resulta poco trascendente, pues en ambos casos, ya sea expresamente o por remisión, se mimetiza y se aplica, en su mayoría, las previsiones del ámbito privado con las particularidades tratadas.

Del mismo modo, se comparte el papel intervencionista de los gobiernos competentes en la negociación funcionarial, pues en ambos modelos se requiere de la aprobación o ratificación de estos para la culminación del proceso llevado a cabo por los representantes de los funcionarios y los de la administración. Sin embargo, en España resulta más flexible esta intervención en la medida en la que no es siempre exigible, sino solamente para las materias que afectan a competencias del poder legislativo o gubernativo; y, sobre todo, esta flexibilidad viene marcada por la libertad o discrecionalidad del gobierno de turno para decidir si aprueba o no los acuerdos alcanzados.

Asimismo, en ambos modelos el protagonismo es asumido en exclusiva por las organizaciones sindicales, al estarles reservadas solo a ellas la legitimación para negociar. No obstante, en España el sistema resulta más abierto en lo que al personal laboral se refiere, al estar legitimados igualmente los representantes legales. Dicho esto, lo cierto es que en Portugal no hay una limitación o restricción de sujetos legitimados, pues en el ámbito privado también son los sindicatos los únicos llamados a negociar, mientras que en España, pese a ser más flexible en comparación con Portugal, sí que se da esta reducción de sujetos legitimados, al excluirse a los representantes legales de la negociación funcionarial. 
Una diferencia importante entre ambos ordenamientos jurídicos es la relativa a la eficacia personal de los acuerdos suscritos. Aunque no es una singularidad del modelo de negociación de la función pública, por cuanto es una característica presente en el conjunto del sistema de relaciones laborales, sí que marca y diferencia ambos modelos. Así pues, en el caso portugués, los acuerdos alcanzados por los sindicatos solamente resultarán de aplicación a los trabajadores afiliados al mismo. Mientras tanto, en España se reconoce y dota de eficacia erga omnes a los acuerdos alcanzados, rigiendo para el conjunto de trabajadores y administraciones que se sitúen dentro del ámbito de aplicación del acuerdo.

Ello explica a su vez dos importantes diferencias: por un lado, la representatividad para ostentar legitimación es menor en el caso portugués que en el español, al tenerse que asegurar, en el este último modelo, que el convenio ha sido aprobado por la mayoría absoluta de los trabajadores afectados. De este modo, la representatividad lusa se articula en función del número de afiliaciones, mientras que la española en torno a los resultados electorales. Por otro lado, en Portugal no rige el principio de unidad de convenio, de tal modo que una misma Administración podrá estar aplicando diferentes acuerdos colectivos al mismo tiempo en función de la afiliación de cada trabajador (o incluso de la elección individual de cada trabajador no afiliado), lo que sin duda conlleva mayor complejidad en la gestión de los recursos humanos.

Si nos fijamos en la estructura de la negociación colectiva, pese a que pudiera pensarse que el modelo español es más rígido, al estar predeterminadas las unidades de negociación directamente por la ley, lo cierto es que la preexistencia de dichas unidades no es más que una garantía para que se entablen y desarrollen procesos de negociación en cada uno de esos niveles, pues pueden abrirse nuevas y complementarias mesas. Por tanto, ambas estructuras se asemejan al contemplar hasta tres tipos de unidades: de negociación general; de negociación sectorial o profesional; y por último, unidades en determinados organismos o entes públicos. La gran diferencia, que de nuevo marca la flexibilidad del modelo español frente al portugués, es la previsión legal de que se articulen mesas comunes de negociación colectiva entre el personal funcionarial y el laboral para que se negocie en una única mesa todas aquellas materias y condiciones de trabajo comunes a ambos tipos de trabajadores.

Desde el punto de vista material, la regulación de la negociación colectiva funcionarial es bastante similar en ambos países, al contemplar la norma un conjunto de materias sobre las que las partes son libres para alcanzar un acuerdo y otras excluidas expresamente. De ahí que, en ambos modelos, se entienda que no se trata de un listado cerrado y se pueda abrir a la negociación de diferentes materias. La diferencia principal, además de la terminológica, es que en España no se incluye en el listado de materias a negociar las normas que deben regir la constitución, modificación y extinción de la relación estatutaria ni tampoco el régimen disciplinario, al encontrarse regulado directamente y en profundidad por las leyes de la Función Pública dictada en desarrollo del Título VII EBEP. En cuanto al personal laboral, sorprende que en Portugal, a diferencia de lo que ocurre en el ámbito privado y funcionarial portugués, y también a diferencia del modelo 
español, no se puede negociar la selección de trabajadores; la carrera profesional y la promoción; el calendario de festivo y descansos; la formación; el régimen disciplinario; y ni siquiera los derechos colectivos. Así pues, en este último sentido, la negociación colectiva laboral lusa resulta mucho más rígida que la española, que se remite al ET con los límites presupuestarios previstos.

No obstante, desde la óptica de contenidos, la mayor diferencia estriba en la intangibilidad de derechos convencionales por la sucesión de acuerdos y pactos. En Portugal existe un riesgo de petrificación en la medida en la que la mera sucesión de regulaciones convencionales, tanto para funcionarios como para personal laboral, no puede justificar por sí sola la disminución de la protección global de los trabajadores. De este modo, aunque pudiera reducirse la intensidad en la protección de una determinada condición laboral, es imprescindible que globalmente la nueva regulación paccionada sea más favorable. Por el contrario, el modelo español es más ágil y flexible, ya que la norma prevé expresamente para ambos tipos de trabajadores que el convenio que sucede a uno anterior puede disponer sobre los derechos reconocidos en aquel, aplicándose íntegramente lo regulado en el nuevo.

Se observa otra diferencia que refuerza la idea de que el modelo español es más flexible, y es que en España sí se contempla desde el año 2012 la posibilidad de dejar de aplicar los acuerdos suscritos si concurren una causa grave de interés público derivada de una alteración sustancial de las circunstancias económicas. En Portugal se debería acudir a la revisión total o parcial del convenio ante tempus para lograr tal objetivo, o, en última instancia, a la primacía de la ley.

Esta flexibilidad del modelo español también está presenta en la regulación de la vigencia y del régimen de ultraactividad frente al modelo portugués, especialmente en lo que concierne a la negociación del personal laboral. En Portugal se exige que la denuncia del convenio se acompañe necesariamente de una propuesta para la revisión del mismo, cuyo procedimiento de renegociación durará como máximo un año y medio durante el cual se seguirán aplicando, en defecto de acuerdo, las cláusulas relativas a la retribución y a la jornada laboral. Eso sí, a partir del mes 12 se puede activar el arbitraje obligatorio para desatascar las negociaciones cuyo laudo tendrá el mismo valor que el convenio colectivo que hubieran alcanzado las partes. En España, por el contrario, una vez producida la denuncia, se mantendrá el total de condiciones laborales solamente durante el primer año, salvo acuerdo en sentido distinto. Una vez agotado, se aplicaría el convenio superior de existir o se contractualizarán las condiciones en caso contrario, sin perjuicio de los sistemas de soluciones extrajudicial previsto en los acuerdos interprofesionales.

\section{Bibliografía}

ALFONSO MELLADO, Carlos L., Los derechos colectivos de los empleados públicos en el Estatuto Básico, Albacete: Bomarzo, 2008. 
DE OLIVEIRA CORREIA, André, "Os , não tão) novos horários de trabalho dos trabalhadores das carreiras gerais: perdidos entre a lei e instrumentos de regulamentação coletiva de trabalho", Questões Laborais, núm. 45, 2014, pp. 372- 390.

LAHERA FORTEZA, Jesús, "La negociación colectiva del personal laboral de las administraciones públicas"; en Ángel Blasco Pellicer y Mercedes López Balaguer (Dirs.), Las relaciones laborales en el Sector Público, Valencia: Tirant lo Blanch, 2019, pp. 998-1027.

LUCAS PIRES, Miguel, Lei Geral do Trabalho em Funçoes Públicas, Coimbra: Almedina, 2016.

MOLL NOGUERA, Rafael, "La negociación colectiva del personal laboral de las Administraciones públicas y su exclusión del convenio sectorial", Trabajo y Derecho: nueva revista de actualidad y relaciones laborales, núm. 69, 2020, pp. 1-29.

MOLL NOGUERA, Rafael, "La descentralización de la negociación colectiva en Portugal y España. Un breve estudio de derecho comparado", Derecho de las relaciones laborales, núm. 10, 2018, pp. 1151-1162.

PEDRO MADEIRA DE, Brito, "O reconhecimento legal do direito à contratação à consolidação", Questões Laborais, num. 45, 2014, pp. 327-347.

ROQUETA BUJ, Remedios, Derecho del Empleo Público, Valencia: Tirant lo Blanch, 2020.

VASCONCELOS ALBUQUERQUE SOUSA, Nuno José, "A reforma do emprego público em Portugal", Questões Laborais, num. 45, 2014, pp. 213-246.

VASCONCELOS ALBUQUERQUE SOUSA, Nuno José, "A reforma do emprego público em Portugal e Espanha", en F. Liberal Fernandes y M. Regina Redinha, Transformações recentes do Direito do Trabalho Ibérico, Porto: UP; 2016, pp. 253-269. 